\title{
Polymorphic variants of genes involved in homocysteine metabolism in celiac disease
}

\author{
Kamil K. Hozyasz • Adrianna Mostowska • \\ Anna Szaflarska-Poplawska $\cdot$ Margarita Lianeri · \\ Pawel P. Jagodzinski
}

Received: 23 November 2010/Accepted: 10 June 2011/Published online: 19 June 2011

(C) The Author(s) 2011. This article is published with open access at Springerlink.com

\begin{abstract}
Celiac disease (CD) is a polygenic chronic enteropathy conferring an increased risk for various nutrient deficiency states. Hyperhomocysteinemia is a frequent finding in $\mathrm{CD}$ and may be related to the development of venous thrombosis, cardiovascular disease, and stroke in untreated CD patients. Recently, a possible excess in the frequency of the MTHFR c.677C $>\mathrm{T}$ (rs1801133) gene variant in CD patients was reported. The purpose of this study was to determine if there exist differences in the distribution of polymorphic variants of genes involved in homocysteine/ methyl group metabolism between $\mathrm{CD}$ patients and the general population. A set of 10 gene polymorphisms (MTHFR rs1801133, MTR rs1805087, MTHFD1 rs2236225, MTRR rs1801394, CBS 844ins68, BHMT1 rs7356530 and rs3733890, BHMT2 rs526264 and rs625879, and TCN2 rs1801198) was tested in 134 patients with $C D$ and 160 matched healthy controls. The frequency of the MTR rs 1805087 GG genotype in CD patients was lower than in controls (0.01 and 0.06, respectively), although statistical
\end{abstract}

Electronic supplementary material The online version of this article (doi:10.1007/s11033-011-1077-7) contains supplementary material, which is available to authorized users.

K. K. Hozyasz ( $\square)$

Department of Pediatrics, Institute of Mother and Child,

17a Kasprzaka Street, 01-211 Warsaw, Poland

e-mail: khozyasz@verco.com.pl

A. Mostowska - M. Lianeri · P. P. Jagodzinski Department of Biochemistry and Molecular Biology, Poznan University of Medical Sciences, Poznan, Poland

A. Szaflarska-Poplawska

Department of Pediatrics, Allergology and Gastroenterology, Collegium Medicum in Bydgoszcz, Nicolaus Copernicus

University, Bydgoszcz, Poland significance was not achieved $(P=0.06)$. For the other analyzed polymorphisms, there was no evidence of difference in both allelic and genotypic distribution between cases and controls. The exhaustive Multifactor Dimensionality Reduction analysis revealed no combination of interactive polymorphisms predicting the incidence of $\mathrm{CD}$. In contrast to the well-documented clinical observations of increased risks of vascular disease in patients with longstanding untreated $\mathrm{CD}$, in our group of patients no significant association with $\mathrm{CD}$ was found for all tested polymorphic variants of genes involved in homocysteine metabolism. These findings should be replicated in studies with a larger sample size.

Keywords MTHFR - MTR - Polymorphisms ·

Celiac disease $\cdot$ Homocysteine

\section{Introduction}

Celiac disease (celiac sprue, CD) is a polygenic chronic enteropathy, resulting from an aberrant cellular response to gluten peptides, which are storage proteins in wheat, barley, and rye. $\mathrm{CD}$ is one of the most common disorders affecting humans with prevalence in populations of Caucasian descent close to 1:100 with the majority of patients awaiting diagnosis [1]. The only treatment is a lifelong strict gluten-free diet.

Increased risks of venous thrombosis, cardiovascular disease, and stroke have been demonstrated in adults with longstanding untreated CD [2-6]. Moreover, a frequent finding in $\mathrm{CD}$ is hyperhomocysteinemia, which may be related to the development of vascular disease in $\mathrm{CD}$ patients [2,7]. Compromised absorptive capacities of vitamins $\mathrm{B}_{6}, \mathrm{~B}_{12}$, and folate in untreated patients make them susceptible to homocysteine abnormalities $[1,8]$. 
Folate is a carrier of one-carbon fragments, which it transfers to various biochemical targets. 5,10-Methylenetetrahydrofolate reductase (MTHFR, EC 1.5.1.20) is one of the critical folate-metabolizing enzymes [9]. It was shown that subjects homozygous for the c677C $>$ T (rs1801133) polymorphism of the MTHFR gene (MIM 607093) had significantly elevated total homocysteine concentrations, whereas the total homocysteine concentration in the $\mathrm{CC}$ subjects did not vary significantly from that in the CT subjects [10]. Genome-wide association study (GWAS) of determinants of plasma homocysteine level showed that the MTHFR c. $677 \mathrm{C}>\mathrm{T}$ is the most significant gene variant [11]. Reduced MTHFR activity could alter the distribution of folate derivatives and the TT genotype is usually associated with a 10-30\% reduction in circulating folate [12]. Either 5-methyltetrahydrofolate, betaine or S-methylmethionine can supply methyl groups for remethylation of homocysteine to methionine. These reactions are catalyzed by vitamin $\mathrm{B}_{12}$-dependent 5-methyltetrahydrofolatehomocysteine methyltransferase (MTR, EC 2.1.1.13), betaine-homocysteine methytransferase 1 and 2 (BHMT1, EC 2.1.1.5; BHMT2, EC 2.1.1.5), respectively. Cystathionine $\beta$-synthase (CBS, EC 4.2.1.22) is involved in the vitamin $\mathrm{B}_{6}$-dependent transsulfuration pathway, which converts homocysteine to cystathionine, a substrate for cysteine synthesis [9]. The methylenetetrahydrofolate dehydrogenase gene (MTHFD1, MIM 172460) encodes a trifunctional enzyme, which catalyses the sequential interconversion of tetrahydrofolate. Methionine synthase reductase (MTRR, EC 2.1.1.135) is involved in the regeneration of methylcobalamin, a cofactor for MTR. The polymorphic variant rs1801198 of the gene for the transcobalamin II protein (TCN2, MIM 613441) has been reported to potentially interfere with the intracellular availability of vitamin $\mathrm{B}_{12}$ [13].

In the prospective study of 40 newly-diagnosed celiac patients and 126 control subjects, Saibeni et al. [8] observed that folate and vitamin $\mathrm{B}_{12}$ levels were independently and inversely associated with homocysteine levels, and homozygosity for the MTHFR $\mathrm{c} .677 \mathrm{C}>\mathrm{T}$ polymorphism tended to reach statistical significance as a risk factor. Abnormalities of homocysteine levels in CD do not consistently improve with a gluten-free diet [14, 15]. It is noteworthy that the small study by Wilcox and Mattia [14] revealed a possible excessive expression of the MTHFR c. $677 \mathrm{C}>\mathrm{T}$ gene variant in $\mathrm{CD}$ patients. Moreover, it is intriguing that despite the high frequency of folate deficiency in untreated celiac patients [16], the suspected association between maternal CD and an increased risk of nonsyndromic structural malformations in CD patient offspring has received no support from large studies focused on unfavourable outcomes of pregnancy in untreated CD women $[17,18]$. The suspected association was considered to be a consequence of hyperhomocysteinemia due to folate deficiency [19-21].

Recently, despite negative clinical observations in untreated CD women, Arakeri et al. [22] postulated a relationship between cleft lip and palate and parental CD, which may be a result of disturbed methylation. Interestingly, there are studies revealing that genetic factors are related to unfavourable pregnancy outcomes in maternal CD, but not the degree of clinical severity of CD [23]. Nuclear magnetic resonance (NMR)-based metabonomics have demonstrated a characteristic signature related to methyl group metabolism for CD [24]. Polymorphic variants of genes involved in methyl group metabolism may modify the susceptibility of carriers to hyperhomocysteinemia and to having children with potentially folate/cobalamin-responsive congenital malformations [9].

Therefore, we hypothesized the existence of differences between $\mathrm{CD}$ patients and the general population in the distribution of polymorphic variants of genes involved in homocysteine metabolism. Using case-control study-based data, we investigated 10 polymorphic variants in 8 genes involved in methyl group homeostasis, which were previously tested by our group as maternal genetic risk factors for orofacial clefts in the Polish population [25, 26].

\section{Materials and methods}

\section{Study population}

Peripheral blood samples from 134 patients with celiac disease (age range 2-30 years, the male-to-female ratio was 0.52 ) were obtained from two Polish referral centers for CD (Collegium Medicum of Nicolaus Copernicus University, Bydgoszcz and Institute of Mother and Child, Warsaw). All affected individuals were diagnosed according to the revised ESPGHAN criteria showing a Marsh III lesion (duodenal villous atrophy with intraepithelial lymphocytosis) and positive tests for anti-endomysium antibodies [1]. In addition, 160 healthy blood donors were used as controls. Frozen whole blood samples for DNA isolation were only available and therefore the participants were not tested for homocysteine and vitamin B levels. All participants were Caucasian of Polish origin. Written informed consent was obtained from all individuals before enrolment in the study. The study was approved by the local Ethics Committee.

Single nucleotide polymorphism selection and genotyping

10 selected single nucleotide polymorphisms (SNPs), with the exception of TCN2 rs1801198, had been previously 
tested by us as maternal risk factors for orofacial clefts in the Polish population [25, 26], and are listed in Table 1. This set of SNPs was chosen based on the following criteria: HapMap validation status, functional relevance and importance, and a minor allele frequency (MAF) of $>0.05$ in the Caucasian population.

DNA was isolated from peripheral blood lymphocytes by salt extraction. Genotyping of all but three polymorphisms was carried out by polymerase chain reaction (PCR), followed by digestion with the appropriate restriction enzyme (PCR-RFLP) and agarose-gel electrophoresis (performed according to the manufacturer's instructions, Fermentas, Vilnius, Lithuania). BHMT1 (MIM602888) rs3733890, BHMT2 (MIM 605932) rs625879, and MTRR (MIM602568) rs1801394 were genotyped by high-resolution melting curve analysis (HRM) on the LightCycler 480 system (Roche Diagnostics, Mannheim, Germany; http:// www.gene-quantification.de/hrm.html). The HRM analysis results were confirmed by DNA sequencing using ABI Prism BigDye Terminator Cycle Sequencing kit and an ABI Prism 3739 capillary sequencer (Applied Biosystems, Foster City, CA, USA). Samples that failed the genotyping assays were excluded from statistical analyses. Details of SNPs selected for genotyping, and the methods of their analysis, are presented in Table 2 .

\section{Statistical analysis}

For each marker, MAF, and Chi-square test for HardyWeinberg equilibrium (HWE) were computed in $\mathrm{CD}$ patients and in controls. The differences in allele and genotype frequencies between cases and controls were determined using standard Chi-square and Fisher exact tests. Statistical power was evaluated by Power and Sample Size Calculation program (http://medipe.psu.ac.th/episoft/ pssamplesize/), Supplementary Table 1. Associations between the investigated polymorphisms and incidence of $\mathrm{CD}$ were tested using the nonparametric and genetic model-free Multifactor Dimensionality Reduction (MDR) approach (MDR version 2.0 beta 5). Statistical significance was evaluated using a 1,000-fold permutation test (MDR permutation testing module 0.4.9 alpha). The MDR software and the MDR permutation testing module are freely available from http://www.epistasis.org. A $P$-value of $<0.05$ was considered statistically significant.

\section{Results}

None of the tested SNPs demonstrated deviation from Hardy-Weinberg equilibrium in either $\mathrm{CD}$ patients or controls. In the patient cases, the MAF for all markers was at least $4 \%$. The genotype frequencies are summarised in Table 3. For the analyzed polymorphisms of MTHFR, MTRR, MTHFD1, CBS (MIM 613381), BHMT1, BHMT2 and $T C N 2$, there was no evidence of a difference in the allelic and genotypic distribution between celiac patients and controls. The frequency of the MTR rs1805087 GG genotype in $\mathrm{CD}$ patients was lower than in controls $(0.01$ and 0.06 , respectively), although statistical significance

Table 1 Characteristics of the polymorphisms genotyped in the data set

\begin{tabular}{|c|c|c|c|c|c|c|c|}
\hline Gene symbol & Gene name & rs no. & $\begin{array}{l}\text { SNP } \\
\text { function }^{\mathrm{a}}\end{array}$ & $\begin{array}{l}\text { Protein } \\
\text { effect }\end{array}$ & Location $^{\mathrm{b}}$ & Alleles ${ }^{c}$ & $\mathrm{MAF}^{\mathrm{d}}$ \\
\hline \multirow[t]{2}{*}{ BHMTl } & \multirow[t]{2}{*}{ Betaine-homocysteine methyltransferase } & rs7356530 & Intergenic & - & chr5:78400908 & $\mathrm{A} / \mathrm{g}$ & 0.44 \\
\hline & & rs3733890 & Missense & Gln239Arg & chr5:78421959 & $\mathrm{a} / \mathrm{G}$ & 0.28 \\
\hline \multirow[t]{2}{*}{ BHMT2 } & \multirow[t]{2}{*}{ Betaine-homocysteine methyltransferase 2} & rs526264 & Intron & - & chr5:78378410 & $\mathrm{a} / \mathrm{T}$ & 0.43 \\
\hline & & rs625879 & Intron & - & chr5:78381689 & $\mathrm{G} / \mathrm{t}$ & 0.43 \\
\hline$C B S$ & Cystathionine-beta-synthase & 844ins68 & $-{ }^{\mathrm{e}}$ & - & chr21:44483195 & W/ins ${ }^{\mathrm{f}}$ & 0.06 \\
\hline MTHFD1 & Methylenetetrahydrofolate dehydrogenase 1 & rs 2236225 & Missense & Arg653Gln & chr14:64908845 & $\mathrm{C} / \mathrm{t}$ & 0.44 \\
\hline MTHFR & 5,10-Methylenetetrahydrofolate reductase & rs1801133 & Missense & Ala222Val & chr1:11856378 & $\mathrm{C} / \mathrm{t}$ & 0.32 \\
\hline$M T R$ & $\begin{array}{l}\text { 5-Methyltetrahydrofolate-homocysteine } \\
\text { methyltransferase }\end{array}$ & rs1805087 & Missense & Asp919Gly & chr1:237048500 & $\mathrm{A} / \mathrm{g}$ & 0.25 \\
\hline$M T R R$ & Methionine synthase reductase & rs1801394 & Missense & Met22Ile & chr5:7870973 & $\mathrm{A} / \mathrm{g}$ & 0.45 \\
\hline TCN2 & Transcobalamin II & rs1801198 & Missense & Arg259Pro & chr22:31011610 & $\mathrm{C} / \mathrm{g}$ & 0.44 \\
\hline
\end{tabular}

${ }^{a}$ According to the Single Nucleotide Polymorphism database (dbSNP)

b Based on UCSC Human Genome Browser, February 2009 human reference sequence (GRCh37)

${ }^{c}$ Uppercase denotes the more frequent allele in the control samples

${ }^{\mathrm{d}} \mathrm{MAF}$, minor allele frequency calculated from the control samples

e 844ins68 is a 68 bp insertion in exon 8 of $C B S$

${ }^{\mathrm{f}} \mathrm{W}$, wild allele; ins, allele with insertion 
Table 2 Conditions for the identification of methyl group metabolism gene polymorphisms

\begin{tabular}{|c|c|c|c|c|c|c|c|c|}
\hline \multirow{2}{*}{$\begin{array}{l}\text { Gene } \\
\text { symbol }\end{array}$} & \multirow[t]{2}{*}{ rs no. } & \multirow[t]{2}{*}{ Primers for PCR amplification $\left(5^{\prime}-3^{\prime}\right)$} & \multirow{2}{*}{$\begin{array}{l}\text { Annealing } \\
\text { temperature } \\
\left({ }^{\circ} \mathrm{C}\right)\end{array}$} & \multirow{2}{*}{$\begin{array}{l}\text { PCR } \\
\text { product } \\
\text { length (bp) }\end{array}$} & \multirow{2}{*}{$\begin{array}{l}\text { Restriction } \\
\text { enzyme }\end{array}$} & \multirow[t]{2}{*}{ Alleles $^{\mathrm{a}}$} & \multicolumn{2}{|c|}{ Restriction fragment length (bp) } \\
\hline & & & & & & & $\begin{array}{l}\text { Genotype } \\
{[1][1]^{\mathrm{b}}}\end{array}$ & $\begin{array}{l}\text { Genotype } \\
{[2][2]^{\mathrm{b}}}\end{array}$ \\
\hline \multirow[t]{4}{*}{ BHMT1 } & rs7356530 & F: GCTTACCACAAGTGAAATGACG & 64.5 & 549 & NlaIII & $\mathrm{A} / \mathrm{g}$ & 316,233 & $316,121,112$ \\
\hline & & R: GGAACTACGCAAATAGCCATC & & & & & & \\
\hline & rs3733890 & F: GTTTCTGGTGCATCCCTAAGT & 64 & 190 & $--^{c}$ & $\mathrm{a} / \mathrm{G}$ & $-^{c}$ & $-^{c}$ \\
\hline & & R: TTGCAGTCAGGAGTGTGGTA & & & & & & \\
\hline \multirow[t]{4}{*}{ ВНMT2 } & rs526264 & F: TGGCAAAGACAGGGAGTAGC & 66 & 576 & MboI & $\mathrm{a} / \mathrm{T}$ & 576 & 329,247 \\
\hline & & R: CAGCTTCTTCAACGTGCTCA & & & & & & \\
\hline & rs625879 & F: TTCTCCCTTTGTCCAGCAAC & 66 & 136 & $--^{c}$ & $\mathrm{G} / \mathrm{t}$ & $-^{\mathrm{c}}$ & $--^{c}$ \\
\hline & & R: TTGAATCTGAGGAGGCCAGA & & & & & & \\
\hline \multirow[t]{2}{*}{$C B S$} & 844ins68 & F: GGGTTTCTCATCCTGCCTCT & 64.2 & 470 & - & W/ins ${ }^{\mathrm{d}}$ & 470 & 538 \\
\hline & & R: TCGTCCCCCAGTCTACTTTG & & & & & & \\
\hline \multirow[t]{2}{*}{ MTHFD1 } & rs2236225 & F: ТTCTTCTCATTCTTCCTCACACC & 66 & 416 & MspI & $\mathrm{C} / \mathrm{t}$ & 255,161 & 416 \\
\hline & & R: TCTGCTCCAAATCCTGCTTC & & & & & & \\
\hline \multirow[t]{2}{*}{ MTHFR } & rs 1801133 & F: AGGCTGTGCTGTGCTGTTG & 67 & 477 & $\operatorname{Hinf\mathrm {I}}$ & $\mathrm{C} / \mathrm{t}$ & 425,52 & $260,165,52$ \\
\hline & & R: CGCTGTGCAAGTTCTGGAC & & & & & & \\
\hline \multirow[t]{2}{*}{ MTR } & rs1805087 & F: GTTGGTGAAGGGAGAAGAAATG & 60 & 583 & HaeIII & $\mathrm{A} / \mathrm{g}$ & 583 & 381,202 \\
\hline & & R: CTGAAGAATGGGGGTCTGTG & & & & & & \\
\hline \multirow[t]{2}{*}{ MTRR } & rs1801394 & F: CCCCATTTTTCAGTTTCACTGT & 53 & 228 & $--^{c}$ & $\mathrm{~A} / \mathrm{g}$ & $-{ }^{c}$ & $--^{c}$ \\
\hline & & R: CACTTCCCAACCAAAATTCTTC & & & & & & \\
\hline \multirow[t]{2}{*}{ TCN2 } & rs1801198 & F: GCATTACAGGTGGGAAAGAGAC & 67.2 & 525 & $M v a \mathrm{I}$ & $\mathrm{C} / \mathrm{g}$ & $363,118,24,17,3$ & $481,24,17,3$ \\
\hline & & R: CCAGGGATCTCCATTTACTGTC & & & & & & \\
\hline
\end{tabular}

${ }^{a}$ Uppercase denotes the more frequent allele in the control samples

b [1], allele $1 ;$ [2], allele 2

c Genotyping with the use of high resolution melting curve analysis (HRM)

${ }^{\mathrm{d}} \mathrm{W}$, wild allele; ins, allele with insertion

was not achieved. The difference between the combined rs1805087 GG + AG genotype frequencies in cases and controls also did not reach significance $(P=0.0842)$. The statistical power of presented study amounted to $50 \%$ for the MTR rs 1805087 GG or AA genotype.

The results of the exhaustive MDR analysis are summarised in Table 4. No combination of possibly interactive polymorphisms reached statistical significance in predicting the incidence of $\mathrm{CD}$.

\section{Discussion}

The present investigation was undertaken to identify potential differences in the distribution of polymorphic variants of genes encoding key proteins of homocysteine metabolism between CD patients and the general population. Hyperhomocysteinemia, which is frequently due to deficiency of B vitamins and is usually, but inconsistently, rapidly corrected by a gluten-free diet in $\mathrm{CD}$, might represent a link between undiagnosed CD and some of its complications $[2,7]$. However, we observed no differences between $\mathrm{CD}$ patients and controls in the prevalence of the common c.677C $>$ T polymorphism of the MTHFR gene, the most important genetic determinant of blood homocysteine concentration in the general population $[9,11]$. Our results regarding the distribution of the MTHFR c. $677 \mathrm{C}>\mathrm{T}$ polymorphism confirm of the results of Dickey et al. [27] and Hadithi et al. [15], who also reported a lack of differences between $\mathrm{CD}$ patients and controls in the prevalence of the MTHFR c. $677 \mathrm{C}>\mathrm{T}$ polymorphism. It is worth mentioning that there was also no difference in the distribution of the T-allele between CD women with at least two pregnancy losses within the first 3 months of pregnancy and CD women with at least one normal pregnancy and no history of spontaneous abortions [23]. In contrast to the suggestions of Wilcox and Mattia (2006), it appears that there is no relevant role in the predisposition of $\mathrm{CD}$ patients to hyperhomocysteinemia and pregnancy complications due to a difference in the distribution of MTHFR c.677C $>\mathrm{T}$ among celiac patients and the general population.

MTR rs1805087 polymorphism analysis showed a borderline difference between the polymorphism's distribution in celiac patients and controls. Although the results regarding the rs1805087 polymorphism's distribution require confirmation in larger studies, they also warrant some comments here. MTR is required by cells for the essential accumulation of folate [28]. The role of the MTR 


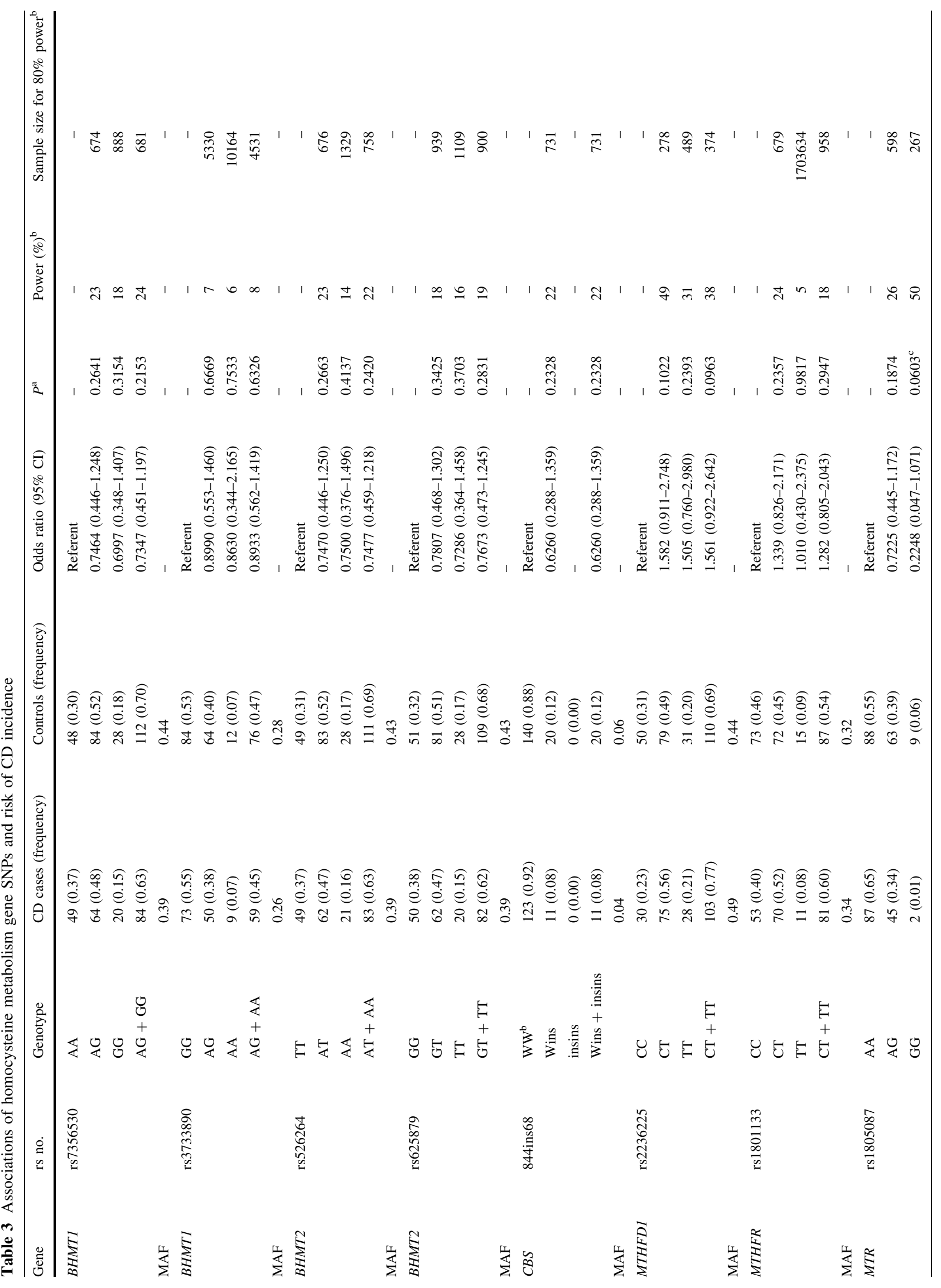




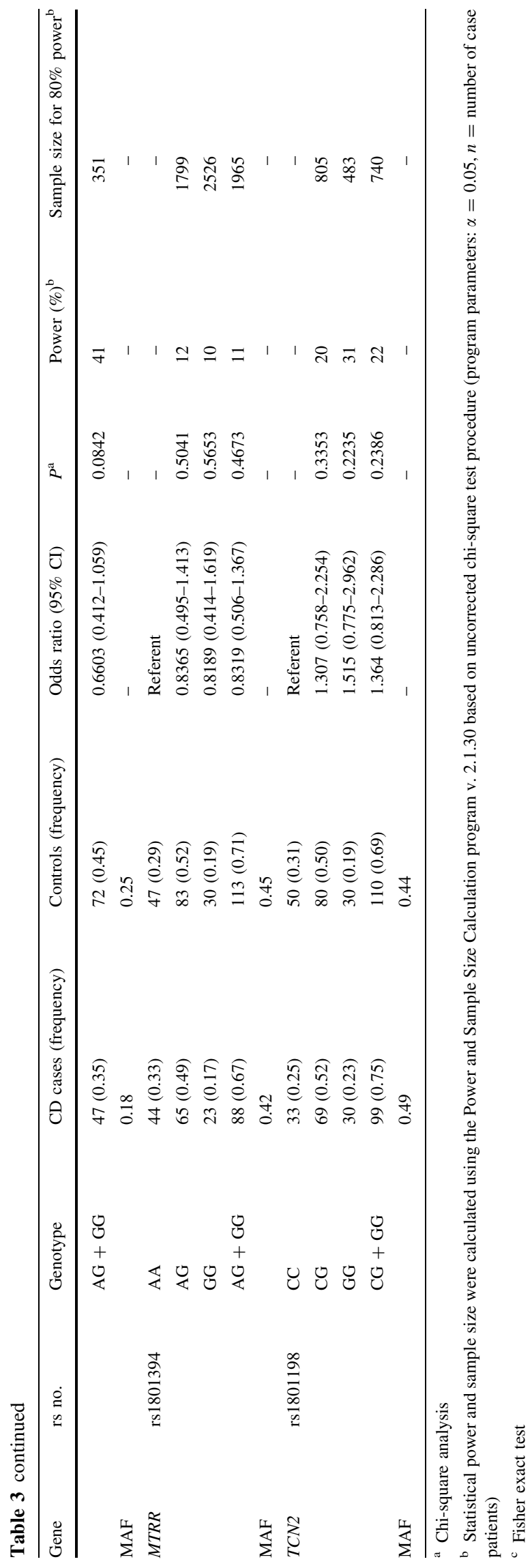

rs1805087 GG genotype in homocysteine homeostasis and genomic methylation is debatable [25]. Rs1805087 has been considerably investigated in humans with structural malformations [29-32]. In our group of celiac patients, the frequencies of the GG genotype and of the combined $\mathrm{AG}+\mathrm{GG}$ genotype tended to be reduced in comparison to controls. The rs1805087 polymorphism, which is a polymorphic transition c. $2756 \mathrm{~A}>\mathrm{G}$ of the $M T R$ gene leading to Asp919Gly substitution, has been shown to increase a woman's risk for giving birth to a child with isolated cleft lip with or without cleft palate in the Polish population [25]. With this in mind, the results of the present study might indicate that Polish CD patients, who carry the $G$ allele less frequently in comparison to the general population, may be less likely to have offspring with structural malformations than controls. There is only one source in the literature of the documented delivery of children with an orofacial cleft by celiac women with increased plasma homocysteine levels [20]. There is a high prevalence of CD in family members of previously diagnosed celiac patients [1]. However, despite a high incidence of both CD and craniofacial malformations in the general population, there are only two case reports, to the best our knowledge, of coexisting $\mathrm{CD}$ and an orofacial cleft (probably syndromic forms) [33, 34]. A literature search and our present observations do not support the hypothesis, recently popularized by Arakeri et al. [22], of a link between parental $\mathrm{CD}$ and orofacial clefts of offspring.

We observed no differences in the distribution of polymorphic variants of MTRR, MTHFD1, BHMT1, BHMT2, and TCN2 between celiac patients and controls. The MDR method has been successfully applied to detecting onecarbon metabolism's gene-to-gene interactions for various diseases [26, 35]. Previous biochemical and metabonomic studies have linked CD and alternations in methyl group metabolism [14, 24]. In contrast to these predictions, in our study the exhaustive MDR analysis revealed no statistically significant interactive effects of the polymorphic variants of the investigated genes on an individual's risk of being affected by CD.

To the best of the authors' knowledge, with the exception of studies devoted to the MTHFR $677 \mathrm{C}>\mathrm{T}$ polymorphism $[8,14,15,23,27]$, this is the first report on the frequency of genes encoding key proteins of homocysteine metabolism in celiac patients, and so we are unable to compare our results with data from other studies. Although the percentage of the MTR rs1805087 GG genotype is sixfold lower in celiac patients than in controls, the absolute number of only two homozygotes among CD patients precludes meaningful statistical comparisons between cases and controls with regard to other possible risk factors. The sample size was small and may strongly influence the presented results. It will be 
Table 4 Results of gene-gene interactions analyzed by MDR method

\begin{tabular}{|c|c|c|c|}
\hline Genes and rs numbers & $\begin{array}{l}\text { Testing balanced } \\
\text { accuracy }^{\text {a }}\end{array}$ & $\begin{array}{l}\text { Cross validation } \\
\text { consistency }^{\mathrm{b}}\end{array}$ & $P$ value ${ }^{\mathrm{c}}$ \\
\hline MTHFD1_rs2236225 & 0.4442 & $4 / 10$ & 0.9980 \\
\hline MTR_rs1805087, TCN2_rs1801198 & 0.5181 & $5 / 10$ & 0.7260 \\
\hline MTHFD1_rs2236225, TCN2_rs1801198, BHMT2_rs625879 & 0.4852 & $7 / 10$ & 0.9480 \\
\hline $\begin{array}{l}\text { MTHFR_rs1801133, MTR_rs1805087, MTRR_rs1801394, } \\
\text { BHMT2_rs526264 }\end{array}$ & 0.5074 & $5 / 10$ & 0.8130 \\
\hline
\end{tabular}

${ }^{a}$ Testing balanced accuracy of classification of cases and controls in the testing dataset calculated as (Sensitivity + Specificity) $/ 2$

${ }^{\mathrm{b}}$ Cross validation consistency is the number of times the model was selected as the best model after tenfold cross validation runs

c Significance of accuracy, empirical $P$ value based on 1,000 permutations

necessary to carry out related studies in larger sample sizes. Moreover, our results may underestimate the true difference in the distribution of the SNPs between celiac patients and controls, as we did not take into account the fact that potentially approx. $1 \%$ of our reference group may also have undiagnosed $\mathrm{CD}[1,36]$. It must be stressed that the selected polymorphisms represent only a fraction of the potential variation of the studied genes.

Restriction or exclusion of all animal foods may result in vitamin $\mathrm{B}_{12}$ deficiency, thereby affecting homocysteine homeostasis. The investigated ethnically homogenous population is mostly omnivorous. Recent studies of $\mathrm{Y}$ chromosome STR haplotype distribution showed homogeneity of paternal lineages in Poland and their distinctiveness from lineages from the neighboring countries [37]. However, weaknesses of our study include the fact that we did not have data on food and supplements intake, as well as on plasma homocysteine and vitamin B levels.

In summary, the present findings revealed no differences in the distribution of polymorphic variants of genes encoding the main proteins involved in homocysteine/ methyl group metabolism between Polish CD patients and controls. The only exception is MTR rs1805087, which tended to be less frequent in celiac patients in comparison to the general population. It may be hypothesized that a lower frequency of rs 1805087 in celiac patients may modify their risk for having offspring with orofacial malformations. The pathophysiology of CD is not yet completely understood [1]. Whether or not there is an increased risk for vitamin B-dependent malformations in offspring of untreated $\mathrm{CD}$ women, despite frequent vitamin B deficiencies, remains an unanswered question and requires further research.

Acknowledgments The technical assistance of Ms Longina Nowak and Ms Joanna Grzelczak is gratefully acknowledged. Supported by grant No. 502-01-01124182-07474, Poznan University of Medical Sciences.
Open Access This article is distributed under the terms of the Creative Commons Attribution Noncommercial License which permits any noncommercial use, distribution, and reproduction in any medium, provided the original author(s) and source are credited.

\section{References}

1. Di Sabatino A, Corazza GR (2009) Coeliac disease. Lancet 373:1480-1493

2. Gefel D, Doncheva M, Ben-Valid E, Wahab-Darausche AE, Lugassy G, Sela B-A (2002) Recurrent stroke in a young patient with celiac disease and hyperhomocysteinemia. Isr Med Assoc J $4: 222-223$

3. Ludvigsson JF, de Faire U, Ekbom A, Montgomery SM (2007) Vascular disease in a population-based cohort of individuals hospitalized with coeliac disease. Heart 93:1111-1115

4. Khanna S, Chaudhary D, Kumar P, Mazumdar S (2008) Occult celiac disease presenting as splenic vein thrombosis. Indian $\mathrm{J}$ Gastroenterol 27:38-39

5. Audia S, Duchene C, Samson M, Muller G, Bielefeld P, Ricolfi F, Giroud M, Besancenot J-F (2008) Stroke in young adults with celiac disease. Rev Med Interne 29:228-231

6. Motovska Z, Widimsky P, Brambaski I, Dvorak M, Julisova I, Kozak T (2009) Haematological manifestation of coeliac disease in a young patient with myocardial infarction. Intern Med J 39:704-706

7. Lim PO, Tzemos N, Farquharson CA, Deegan P, MacWalter RS, Struthers AD, MacDonald TM (2002) Reversible hypertension following coeliac disease treatment: the role of moderate hyperhomocysteinaemia and vascular endothelial dysfunction. J Hum Hypertens 16:411-415

8. Saibeni S, Lecchi A, Meucci G, Cattaneo M, Tagliabue L, Rondonotti E, Formenti S, De Franchis R, Vecchi M (2005) Prevalence of hyperhomocysteinemia in adult gluten-sensitive enteropathy at diagnosis: role of B12, folate, and genetics. Clin Gastroenterol Hepatol 3:574-580

9. Fox JT, Stover PJ (2008) Folate-mediated one-carbon metabolism. Vitam Horm 79:1-44

10. Jacques PF, Bostom AG, Williams RR, Ellison RC, Eckfeldt JH, Rosenberg IH, Selhub J, Rozen R (1996) Relation between folate status, a common mutation in methylenetetrahydrofolate reductase, and plasma homocysteine concentrations. Circulation 93:7-9 
11. Tanaka T, Scheet P, Giusti B, Bandinelli S, Piras MG, Usala G, Lai S, Mulas A, Corsi AM, Vestrini A, Sofi F, Gori AM, Abbate R, Guralnik J, Singleton A, Abecasis GR, Schlessinger D, Uda M, Ferrucci L (2009) Genome-wide association study of vitamin B6, vitamin B12, folate, and homocysteine blood concentrations. Am J Hum Genet 84:477-482

12. Christensen KE, Rozen R (2010) Genetic variation. Effect on folate metabolism and health. In: Bailey LB (ed) Folate in health and disease. CRC Press, Boca Raton, pp 75-110

13. von Castel-Dunwoody KM, Kauwell GP, Shelnutt KP, Vaughn JD, Griffin ER, Maneval DR, Theriaque DW, Bailey LB (2005) Transcobalamin $776 \mathrm{C} \rightarrow \mathrm{G}$ polymorphism negatively affects vitamin B12 metabolism. Am J Clin Nutr 81:1436-1441

14. Wilcox GM, Mattia AR (2006) Celiac sprue, hyperhomocysteinemia, and MTHFR gene variants. J Clin Gastroenterol 40: 596-601

15. Hadithi M, Mulder CJ, Stam F, Azizi J, Crusius JB, Penã AS, Stehouwer CD, Smulders YM (2009) Effect of B vitamin supplementation on plasma homocysteine levels in celiac disease. World J Gastroenterol 15:955-960

16. Cooke WT, Holmes GK (1984) Coeliac disease. Churchill Livingstone, Edinburgh, pp 123-128

17. Greco L, Veneziano A, Di Donato L et al (2004) Undiagnosed celiac disease does not appear to be associated with unfavourable outcome of pregnancy. Gut 53:149-163

18. de Almeida RC, Lima BO, Castro LC, Gandolfi L, Pratesi R (2009) Maternal celiac disease: improbable risk factor for neural tube defect. Eur J Gastroenterol Hepatol 21:805-808

19. Stazi AV, Mantovani A (2000) A risk factor for female fertility and pregnancy: celiac disease. Gynecol Endocrinol 14:454-463

20. Hozyasz KK (2000) Pregnancy outcomes in celiac women. Am J Gastroenterol 95:1373-1374

21. Rostami K, Steegers EA, Wong WY, Braat DD, Steegers-Theunissen RP (2001) Coeliac disease and reproductive disorders: a neglected association. Eur J Obstet Gynecol Reprod Biol 96:146-149

22. Arakeri G, Arali V, Brennan PA (2010) Cleft lip and palate: an adverse pregnancy outcome due to undiagnosed maternal and paternal coeliac disease. Med Hypotheses 75:93-98

23. Ciacci C, Tortora R, Scudiero O, Di Fiore R, Salvatore F, Castaldo G (2009) Early pregnancy loss in celiac women: the role of genetic markers of thrombophilia. Dig Liv Dis 41:717-720

24. Bertini I, Calabro A, De Carli V, Luchinat C, Nepi S, Porfirio B, Renzi D, Saccenti E, Tenori L (2009) The metabonomic signature of celiac disease. J Proteome Res 8:170-177

25. Mostowska A, Hozyasz KK, Jagodzinski PP (2006) Maternal MTR genotype contributes to the risk of non-syndromic cleft lip and palate in the Polish population. Clin Genet 69:512-517
26. Mostowska A, Hozyasz KK, Biedziak B, Misiak J, Jagodzinski PP (2010) Polymorphisms located in the region containing BHMT and BHMT2 genes as maternal protective factors for orofacial clefts. Eur J Oral Sci 118:325-332

27. Dickey W, Ward M, Whittle CR, Kelly MT, Pentieva K, Horigan G, Patton S, McNulty H (2008) Homocysteine and related B-vitamin status in celiac disease: effects of gluten exclusion and histological recovery. Scand J Gastroenetrol 43:682-688

28. Deng L, Elmore CL, Lawrance AK, Matthews RG, Rozen R (2008) Methionine synthase reductase deficiency results in adverse reproductive outcomes and congenital heart defects in mice. Mol Genet Metab 94:336-342

29. Doolin MT, Barbaux S, McDonnell M, Hoess K, Whitehead AS, Mitchell LE (2002) Maternal genetic effects, exerted by genes involved in homocysteine remethylation, influence the risk of spina bifida. Am J Hum Genet 71:1222-1226

30. Goldmuntz E, Woyciechowski S, Renstrom D, Lupo PJ, Mitchell LE (2008) Variants of folate metabolism genes and the risk of conotruncal cardiac defects. Circ Cardiovasc Genet 1:126-132

31. Brandalize AP, Bandinelli E, Borba JB, Félix TM, Roisenberg I, Schüler-Faccini L (2007) Polymorphisms in genes MTHFR, MTR and MTRR are not risk factors for cleft lip/palate in South Brazil. Braz J Med Biol Res 40:787-791

32. Shaw GM, Lu W, Zhu H, Yang W, Briggs FB, Carmichael SL, Barcellos LF, Lammer EJ, Finnell RH (2009) 118 SNPs of folaterelated genes and risks of spina bifida and conotruncal heart defects. BMC Med Genet 10:49

33. Intiso D, Cioffi R, Di Viesti P, Simone P, Tonali P (1998) Bilateral periventricular nodular heterotopias associated with coeliac disease and palatoschisis. Ital J Neurol Sci 19:180-183

34. Ounap K, Ilus T, Laidre P, Uibo O, Tammur P, Bartsch O (2005) A new case of $2 q$ duplication supports either a locus for orofacial celfting between markers D2S1897 and D2S2023 or a locus for cleft palate only on chromosome 2q13-q21. Am J Med Genet 137A:323-327

35. Naushad SM, Pavani A, Digumarti RR, Gottumukkala SR, Kutala VK (2010) Epistatic interactions between loci of one-carbon metabolism modulate susceptibility to breast cancer. Mol Biol Rep. doi:10.1007/s11033-010-0631-z

36. Szaflarska-Poplawska A, Parzecka M, Muller L, Placek W (2009) Screening for celiac disease in Poland. Med Sci Monit 15:PH7-11

37. Wozniak M, Grzybowski T, Starzynski J, Marciniak T (2007) Continuity of $\mathrm{Y}$ chromosome haplotypes in the population of Southern Poland before and after the Second World War. Forensic Sci Int Genet 1:134-140 